\title{
Level of Satisfaction of Buffalo Farmers in their Interaction with Stakeholders
}

\author{
Kamal Kumar $^{1 *}$, Mahesh Chander ${ }^{1}$, V. B. Dixit ${ }^{3}$ and Lalita Garg ${ }^{2}$ \\ ${ }^{1}$ Division of Extension Education, ${ }^{2}$ Division of Livestock Products Technology, Indian \\ Veterinary Research Institute, Izatnagar, Bareilly (Uttar Pradesh), India \\ ${ }^{3}$ Central Institute for Research on Buffaloes, Hisar (Haryana) \\ *Corresponding author
}

\begin{abstract}
A B S T R A C T
\section{Keywords}

Buffalo farmers,

Haryana,

Information

providing

stakeholders, Level

of satisfaction

\section{Article Info}

Accepted:

16 November 2020

Available Online:

10 December 2020

The present study was conducted in three districts of Haryana. The sample of the study was buffalo farmers. Total twelve villages were part of the study and ten farmers were selected randomly from each village thus making the sample size to 120 buffalo farmers. An ex-post facto research design was followed in this study. Data on the level of satisfaction perceived by the farmers with regard to their interaction with information providing stakeholders was collected on a three-point continuum. Scores of 3,2 and 1 were assigned to full satisfaction, moderate satisfaction and not satisfied, respectively. On the basis of mean total score different areas were ranked according to their level of satisfaction and breeding area was ranked first followed by healthcare, management, feeding, market and farm credit were ranked second, third, fourth, fifth and sixth, respectively. It was found that 42.50 per cent of the respondents had a medium satisfaction followed by 30.80 per cent respondents had a low satisfaction, while only 26.70 per cent respondents had a high satisfaction from information providing stakeholders.
\end{abstract}

\section{Introduction}

In India, most of the population depends on agriculture and livestock production which are linked to each other in various aspects. In turn, the bulk of them rely upon the livestock sector directly or indirectly for his or her subsistence. This sector is providing employment to eighty per cent of the population and livelihood to twenty six million people. The country has around 2.29 per cent surface area of the planet and sustaining 11.60 per cent of the planet livestock population. India possesses the biggest husbandry sector of the globe with around 512.06 million livestock heads (GOI, $2017^{b}$ ).

Moore (2002) argued that within the modern era, dissemination of data and applying information within the process of agricultural production will play a significant role within the development of farm settlements. Animal health information is of potential importance not only to the farm-firm business but potentially also to animal welfare and public 
health. It's against this background that the field of agriculture isn't an exception within the need for timely delivery of complete and relevant agriculture information. This can be because buffalo farmers have varying needs that range from information on the disease status of animals which is incredibly crucial and may contribute to an outsized number of herd die out when ignored or pose as a threat to the well-being of humans. Buffalo farmers also need information on good husbandry practices, new emerging technologies, market-related information, and knowledge on livestock policies.

Furthermore, understanding how farm and farmer's demographic characteristics influence the search of knowledge and use of varied sources may provide insights into this study. Relevant information forms the idea for sound decisions of buffalo husbandry practices. Lack of data on buffalo husbandry health practices ultimately ends up in production losses through morbidity and sometimes mortality all leading to economic losses to the buffalo owners. This, therefore, entails that this particular group of farmers require information to create sound decision to extend the assembly level of the buffaloes.

Demiryurek et al., (2008) revealed that information is a vital factor that interacts with other production factors like land, labor, capital, and managerial ability and may arguably be improved by relevant, reliable and useful information. Farmer centric and context specific information has more satisfaction. This study was done to assess the perceived level of satisfaction of buffalo farmers in their interaction with information providing stakeholders.

\section{Materials and Methods}

The present study was carried out in Haryana. Three districts were selected randomly and two blocks from each randomly selected district formed part of the study. From each block two villages were selected thus twelve villages constituted the study area. Ten farmers from each village were selected randomly to arrive at a total sample size of 120 farmers.

An ex- post facto research design was used in the present study. Data on the level of satisfaction perceived by the farmers with regard to their interaction with information providing stakeholders was collected on a three-point continuum. Scores of 3, 2 and 1 were assigned to full satisfaction, moderate satisfaction and not satisfied, respectively.

\section{Results and Discussion}

Level of satisfaction perceived by the farmers

Respondents interacted with the information providing stakeholders through different modes regarding their information needs. The findings of the same are explained as under:

Ranking of areas of information needs of respondents' on the basis of their satisfaction

Data on the level of satisfaction of respondents on different areas of information needs about improved buffalo husbandry practices were collected and on the basis of their mean scores, the different areas were ranked. The findings are presented as under.

As shown in Table 1, on the basis of mean total score different areas were ranked according to their level of satisfaction and breeding area was ranked first followed by healthcare, management, feeding, market and farm credit were ranked second, third, fourth, fifth and sixth, respectively. 
Distribution of respondents according to their level of satisfaction with regard to their interaction with stakeholders

Data on the level of satisfaction perceived by the farmers with regard to their interaction with stakeholders was collected on a threepoint continuum. The findings of the same are presented as below.

As Table 2 indicates that 42.50 per cent of the respondents had a medium satisfaction followed by 30.80 per cent respondents had a low satisfaction, while only 26.70 per cent respondents had a high satisfaction from information providing stakeholders. The results were in line with the findings of Deekshit (2015) who conducted a study on perception of livestock farmers on service delivery systems in Andhra Pradesh and reported that majority of the dairy farmers were having the medium level of perception from public service delivery system private service delivery system.

Table.1 Area wise ranking of information needs of farmers with regard to their satisfaction of interaction

\begin{tabular}{|c|c|c|}
\hline Areas of interaction & Mean level of satisfaction & Rank \\
\hline General management & 2.00 & III \\
\hline Breeding & 2.10 & I \\
\hline Healthcare & 2.03 & II \\
\hline Feeding & 1.96 & IV \\
\hline Market & 1.96 & V \\
\hline Farm credit & 1.93 & VI \\
\hline
\end{tabular}

Table.2 Distribution of respondents according to their level of satisfaction

\begin{tabular}{|c|c|}
\hline Level of satisfaction from stakeholders & Frequency $(\mathbf{n}=\mathbf{1 2 0})$ \\
\hline Low & $37(30.80)$ \\
\hline Medium & $51(42.50)$ \\
\hline High & $32(26.70)$ \\
\hline & Mean total score $=\mathbf{1 8 . 5 7}$ \\
\hline
\end{tabular}

Table.3 Distribution of respondents according to their level of satisfaction

\begin{tabular}{|c|c|c|c|c|}
\hline Stakeholders & FS & MS & NS & Mean \\
\hline Scientist & $8(6.70)$ & $77(64.20)$ & $35(29.20)$ & 1.78 \\
\hline SDAH functionaries & $46(38.33)$ & $45(37.50)$ & $29(24.17)$ & 2.14 \\
\hline Govt. agencies & $22(18.33)$ & $72(60.00)$ & $26(21.67)$ & 1.97 \\
\hline Farmer cooperatives & $72(60.00)$ & $39(32.50)$ & $9(7.50)$ & 2.53 \\
\hline Private agencies & $53(44.16)$ & $49(40.84)$ & $18(15.00)$ & 2.29 \\
\hline Dairy cooperatives & $2(1.67)$ & $66(55.00)$ & $52(43.33)$ & 1.58 \\
\hline NGOs & $29(24.20)$ & $39(32.50)$ & $52(43.33)$ & 1.81 \\
\hline Administrators & $2(1.67)$ & $53(44.16)$ & $65(54.16)$ & 1.48 \\
\hline Other farmers & $73(60.84)$ & $29(24.16)$ & $18(15.00)$ & 2.46 \\
\hline
\end{tabular}

FS- Full satisfaction, MS- Moderate satisfaction, NS- Not satisfied 
Table.4 Ranking of stakeholders according to level of perceived satisfaction of farmers' with regard to interaction

\begin{tabular}{|c|c|c|}
\hline Stakeholders & Satisfaction perceived (\%) & Rank \\
\hline Scientist & 71.10 & VI \\
\hline SDAH functionaries & 75.30 & V \\
\hline Government input agencies & 77.50 & IV \\
\hline Farmers' cooperatives & 93.70 & I \\
\hline Private input agencies & 87.30 & III \\
\hline Dairy cooperatives & 59.10 & VIII \\
\hline NGOs & 59.10 & VII \\
\hline Administrators and planners & 45.10 & IX \\
\hline Other farmers & 85.30 & II \\
\hline
\end{tabular}

Table.5 Relationship of farmers' antecedent variables with their level of satisfaction of interaction with stakeholders

\begin{tabular}{|c|c|}
\hline Antecedent variable & Correlation with total score of satisfaction \\
\hline Caste & $0.243^{* *}$ \\
\hline Education & $0.161^{*}$ \\
\hline Herd size & $0.150^{* *}$ \\
\hline Landholding & $0.293^{* *}$ \\
\hline Livestock gross annual income & $0.253^{* *}$ \\
\hline Total gross annual income & $0.512^{* *}$ \\
\hline Mass media exposure & $0.753^{* *}$ \\
\hline Extension agency contact localite & $0.617^{* *}$ \\
\hline Extension agency contact & $0.861^{* *}$ \\
\hline cosmopolite & $0.419^{* *}$ \\
\hline Social participation & \\
\hline
\end{tabular}

** - Significant at 0.01 per cent, * - Significant at 0.05 per cent

Table.6 Contribution of farmers' antecedent variables to their level of satisfaction of stakeholders

\begin{tabular}{|c|c|}
\hline Antecedent variable (predictors) & \multicolumn{2}{|c|}{ Regression coefficient with stakeholders } \\
\hline Extension agency contact cosmopolite & $\mathbf{R}^{\mathbf{2}=\mathbf{0 . 7 8 1}}$ \\
\hline Mass media exposure & $\mathbf{F}=\mathbf{1 3 7 . 5 7}^{* *}$ \\
\hline Extension agency contact localite & \\
\hline ** - Significant at 0.01 per cent, ${ }^{*}$ - Significant at 0.05 per cent & \\
\hline
\end{tabular}

Similar results were also reported by Chaturvedani et al., (2016) who studied the satisfaction level of livestock owners towards the delivery of veterinary services in
Chhattisgarh and reported that large proportion of livestock owners $(45.56 \%)$ had a medium level of satisfaction with state veterinary services. 
Distribution of respondents according to their level of satisfaction with regard to their interaction with different stakeholders

As shown in Table 3 the majority of the respondents $(64.20 \%)$ had moderate satisfaction as for as their interaction with scientists was concerned, while 29.20 per cent respondents were not satisfied whereas, 38.33 per cent of respondents were having full satisfaction with SDAH field functionaries followed by 37.50 per cent who had moderate satisfaction. Similar observations were reported by Chand et al., (2014) who conducted a study on Farmers' satisfaction with delivery of veterinary services in Rajasthan and reported that a large proportion of farmers $(38.66 \%)$ were having medium level of satisfaction with veterinary services provided by department of animal husbandry and they were very satisfied with the information about diseases outbreaks and vaccination.

Most $(60.00 \%)$ of the farmers had moderate satisfaction from government input agencies followed by 21.67 per cent who were not satisfied, while from private input agencies 44.16 per cent farmers were fully satisfied followed by 40.84 per cent who were moderately satisfied.

More than half $(60.00 \%)$ of the buffalo farmers had full satisfaction from farmers' cooperatives, followed by 32.50 per cent with moderate satisfaction while from dairy cooperatives most of the respondents $(55.00 \%)$ had moderate satisfaction followed by 43.33 per cent who were not satisfied. Results were in line with the findings of Nishi et al., (2011) who conducted a study on Dairy Farmers' Satisfaction with Dairy cooperatives and found that about one third of the respondents were satisfied with the dairy cooperatives.
Amongst themselves, more than half $(60.84 \%)$ of the farmers' had full satisfaction followed by 24.16 per cent having moderate satisfaction. More than half $(54.16 \%)$ of the farmers were not satisfied with regard to their interaction with administrators and planners followed by 44.16 per cent who had moderate satisfaction, while 43.33 per cent of the respondents were not satisfied with their interaction with NGOs' followed by 32.50 per cent who were moderately satisfied.

\section{Ranking of stakeholders according to their perceived satisfaction of interaction}

Stakeholders, by the farmers were ranked on the basis of mean scores regarding their perceived satisfaction and findings are presented in the table below:

As evident from Table 4 various information providing stakeholders viz., farmers' cooperatives, farmers, private agencies, government agencies, state department of animal husbandry field functionaries, scientist, administrators and planners, dairy cooperatives and NGOs were ranked first, second, third, fourth, fifth, sixth, seventh, eighth, ninth and tenth, respectively on the basis of mean percentage satisfaction perceived by the respondents.

\section{Correlation of farmers' antecedent variables with level of satisfaction of stakeholders}

To determine the association of the antecedent variables with their perceived level of satisfaction, the data were subjected to correlation analysis. It is apparent from Table 5 that all the antecedent variables were positively and significantly correlated with the level of satisfaction of respondents, from different information providing stakeholders. The antecedent variables which positively and significantly related with regard to perceived satisfaction of farmers with stakeholders were 
extension agency contact cosmopolite followed by mass media exposure, localite extension agency contact, social participation, total gross annual income, landholding, caste, herd size and education. The results were in concurrence with Deekshit (2015), who conducted a study on perception of livestock farmers on service delivery systems in Andhra Pradesh, reported that mass media exposure and extension agency contact were positively and non-significantly related with the level of perception of respondents from service delivery systems.

Stepwise regression analysis of farmers' antecedent variables with their level of satisfaction of stakeholders

To determine the contribution of antecedent variables to their level of satisfaction, data were subjected to stepwise regression analysis. As indicated in Table 6, the stepwise regression analysis of the data reveals that the level of satisfaction from different stakeholders was explained by three antecedent variables viz., cosmopolite extension agency contact, mass media exposure and localite extension agency contact to the extent of 78.10 per cent.

In conclusion the farmers had a medium level of perceived satisfaction on areas of information needs and from the information providing stakeholders with regard to their interaction. Extension agency contact cosmopolite, mass media exposure and extension agency contact localite contributed positively and significantly towards their level of satisfaction. The level of satisfaction of farmers' can be increased by providing them context specific and need based information in local languages through meetings, Kisan gosthis, off-campus training, newspapers, buffalo husbandry dedicated television programs, etc.

\section{References}

Chand, S., Meena, B.S. and Verma, H.C. 2014. A study on farmers' satisfaction with delivery of veterinary services. Indian Journal of Animal Research, 48(1): 67-70 DOI: 10.5958/j.0976-0555.48.1.014.

Chaturvedani, A.K., Niranjan, L., Dhruw and Kalpana. 2016. Satisfaction level of livestock owners towards delivery of veterinary services. International Journal of Bioresource and stress management, 7(6): 1392-1395

Deekshit, G.V. 2015. A study on perception of livestock farmers on service delivery systems in Andhra Pradesh. M.V.Sc. Thesis, SVVU, Tirupati, Andhra Pradesh, India. Accessed throughhttp://krishikosh.egranth.ac.in/bits tr

am/1/90356/1/VENKATA\%20DEEKSHI T\% 20G.pdf on 10.5.2019.

Demiryurek, K. 2008. The use of social network analysis (SNA) to identify opinion leaders: the case of organic hazelnut producers in Turkey Journal of Extension Systems, 24: 17-30.

Government of India. 2017b. 19th Livestock Census 2012, Ministry of Agriculture and Farmers Welfare, Department of Animal Husbandry, Dairying and Fisheries, Krishi Bhawan, New Delhi Accessed through http://dahd.nic.in/sites/default/filess/ Livestock\%20\%205_0.pdf on 05.09.2018.

Moore, N. 2002. A model of social information need. Journal of Information Science, 28(4): 297-303.

Nishi, Sah, A.K. and Kumar, R. 2011. Dairy farmers' satisfaction with dairy cooperatives: A case study. Indian Research Journal of Extension Education, 11(1):74-78.

\section{How to cite this article:}

Kamal Kumar, Mahesh Chander, V. B. Dixit and Lalita Garg. 2020. Level of Satisfaction of Buffalo Farmers in their Interaction with Stakeholders. Int.J.Curr.Microbiol.App.Sci. 9(12): 22892294. doi: https://doi.org/10.20546/ijcmas.2020.912.271 